Teknokultura. Revista de Cultura Digital y Movimientos Sociales

ISSNe: $1549-2230$

https://dx.doi.org/10.5209/TEKN.68540

\title{
Maquinaria, ordenadores y superación del capital: una aproximación crítica al ciber-comunismo
}

\author{
Jesús Rodríguez Rojo ${ }^{1}$
}

Recibido: 29 de marzo de 2020 / Aceptado: 30 de junio de 2020 Open peer reviews

Resumen. Este artículo ofrece un balance crítico de la propuesta ciber-comunista abanderada hoy por autores como Cockshott, Cottrell y Nieto. Trataremos de ver si la computación ofrece los elementos necesarios para llevar a cabo una revolución de las condiciones de producción que dejen atrás las formas mercantiles y fetichizadas que hoy parecemos requerir para satisfacer nuestras necesidades. Para ello la examinamos a la luz de los desarrollos que la crítica marxista de la economía política ofrece sobre la forma en que tiene lugar la superación del modo de producción capitalista. El núcleo de la argumentación se ceñirá a discernir hasta qué punto y en qué sentido la ciber-tecnología consigue profundizar los cambios que Marx identificaba con la implantación de la maquinaria como forma de extracción de plusvalía relativa.

Palabras clave: comunismo; marxismo; planificación económica; socialismo.

\section{[en] Machinery, computers and overcoming capital: a critical approach to cyber- communism}

Abstract. This article provides a critical assessment of the cyber-communist proposal mainly defended today by authors such as Cockshott, Cottrell and Nieto. We will analyze if computing offers the necessary elements to carry out a revolution in the conditions of production that may leave behind the mercantile and fetishized forms, we seem to require today to satisfy our needs. To that end, we examined it in the light of the developments that Marxist criticism of political economy offers about how the capitalist mode of production overcomes itself. The core of the argument will be limited to discerning to what extent and in what sense cyber-technology manages to deepen the changes that Marx identified with the introduction of machinery as a form of extraction of relative surplus value.

Keywords: communism; economic planning; Marxism; socialism.

Sumario. 1. Introducción. 2. La superación del capital... en El capital. 3. La propuesta ciber-comunista. 4. Ordenadores y transición al socialismo. 5. Conclusiones. 6. Referencias.

Cómo citar: Rodríguez Rojo, J. (2020). Maquinaria, ordenadores y superación del capital: una aproximación crítica al ciber-comunismo. Teknokultura. Revista de Cultura Digital y Movimientos Sociales, 17(2), 113-120.

\section{Introducción}

Pareciera que es un asunto trasnochado el pensar cómo de nuestra sociedad puede nacer una nueva que dé respuestas a muchos de los problemas que hoy tenemos. Lo inmediato, a veces excusado en el pragmatismo impuesto como límite de la aproximación a la realidad, invade nuestros marcos cognitivos. Son pocos los académicos que se aventuran a ofrecer una explicación sobre cómo la humanidad puede desprenderse del modo de producción capitalista. De entre ellos, aquí prestaremos atención a una serie de propuestas que aglutinamos bajo el rótulo del 'ciber-comunismo'. Esta corriente, cuya figura más prominente es el economista e informático escocés P. Cockshott, tuvo su hito fundacio- nal a comienzos de los años noventa, con la publicación de Towards a New Socialism. En esta obra y otras tantas posteriores, él y sus (más o menos cercanos) epígonos tratan de postular los principios rectores de un mecanismo que satisfaga de forma eficiente las necesidades sociales esquivando las formas mercantiles. Sus contribuciones, reclamándose herederas de la obra de Marx, aspiran a demostrar que el capitalismo actual puede ser sustituido por un mejor modo de producción con medios que hoy tenemos al alcance de la mano. Nuestra pretensión en este trabajo no es otra que la de examinar si tal proyecto puede encajarse y de qué manera en la elaboración sobre la superación del capital que encontramos formulada en la crítica de la economía política. 
Para llevar a cabo este propósito, nos vemos obligados a comenzar por exponer, siquiera sea de manera telegráfica, la forma en la que, inspirándonos en Marx, creemos que puede tener lugar dicha superación; con este propósito trataremos de sintetizar algunos de los despliegues lógicos fundamentales de El capital -cabe destacar la importancia de las contribuciones de los autores del Centro para la Investigación como Crítica Práctica para la formulación de este desarrollo (especialmente: Iñigo Carrera, 2013; Starosta, 2015; Starosta y Caligaris, 2017)-. Tras ello expondremos sintéticamente la elaboración ciber-comunista, resumiendo conjuntamente sus más importantes contribuciones, asumiendo (tal vez de forma algo precipitada) que no existen diferencias sustanciales que exijan un trato diferenciado. Al final, vendrá una crítica que, más que señalar los defectos o aporías que, a nuestro juicio, existan, procura generar las condiciones para una propuesta superadora. Aspiramos así a ofrecer un balance rico y complejo sobre esta interesante propuesta rescatando sus más valiosas aportaciones.

\section{La superación del capital... en El capital}

En una sociedad de productores independientes y recíprocamente libres, en la que las necesidades se cubren a través de relaciones mercantiles, el metabolismo social funciona al margen de la voluntad de quienes en él participan. El valor, expresión social de los valores de uso en estas condiciones históricas, queda como el nexo enajenado que se establece entre los productores (Marx, 1973a). Pero para poder investirse como rector de la sociedad debe renunciar sucesivamente a formas mercantil y dineraria deviniendo un proceso autónomo. Es así como nace el capital: el valor "pasa constantemente de una forma a otra" convirtiéndose en un "sujeto automático" preocupado únicamente por incrementarse (Marx, 1973a, p. 117). Para consumar esta compulsiva valorización, el capital escinde su voluntad y su capacidad de hacerlo. Surgen de un lado los propietarios de los medios de producción, personificaciones del capital, que reflejan sus necesidades como un "fin subjetivo" (Marx, 1973a, p. 116); y de otro quienes, desposeídos, se incorporan al proceso de producción vendiendo su "fuerza de trabajo" (Marx, 1973a, pp. 129-38). De la semilla de la forma de organizar el trabajo social brotan, entonces, las clases sociales.

Una vez consumada la compraventa de la fuerza de trabajo, el trabajo mismo queda, al ser consumido productivamente, subsumido en el capital, lo que se expresa como una relación de subordinación al capitalista. Será este el responsable de "vigilar que [... el] trabajo se ejecute como es debido y que los medios de producción se empleen convenientemente" (Marx, 1973a, p. 147). A partir de ahí, si cada cual cumple su función, el capital conseguirá valorizarse al vender el producto preñado del plusvalor que el obrero aporta con su trabajo una vez rebasado el valor de su propia fuerza de trabajo. Para aumentar la cantidad de plusvalía obtenida -incrementando la tasa de plusvalía-, el capital cuenta con dos es- trategias. Una sería incrementar la jornada laboral, plusvalía absoluta, y la otra, reducir el valor de la fuerza de trabajo, plusvalía relativa.

Establecer y reglamentar la duración del lapso de trabajo "se revela como una lucha en torno a los límites de la jornada" (Marx, 1973a, p. 192): su dilatación, que sería el fin inmediato de todo capitalista, lleva aparejada la resistencia de las plantillas. Este choque de voluntades acaba mostrando la rigidez del factor en cuestión. La necesidad de reproducir la fuerza de trabajo, vendiéndola por su valor, obliga al capital a establecer una jornada normal que no acabe dando al traste con la fuente de su riqueza. Este límite, evidenciado por la lucha de la clase obrera, le fuerza a implementar la más potente forma de incrementar la tasa de plusvalía: rebajar el valor de la propia fuerza de trabajo.

Para disminuir este montante debe incrementarse la capacidad productiva del trabajo en las ramas que producen los medios de consumo obreros. En los capitalistas individuales se refleja esta pretensión al tratar de hacerse con la plusvalía extraordinaria que brota cuando sus trabajadores tienen una productividad superior a la normal, reducir el tiempo en que producen las mercancías. Con este propósito, comienzan por reunir en un entorno común cierto número de obreros que realizan labores similares, así se economiza el empleo de los medios de producción y cada obrero se puede nutrir de las prácticas de sus compañeros. Se revolucionan las "condiciones objetivas del proceso de trabajo, aunque el régimen de trabajo no varíe" (Marx, 1973a, p. 280). La incorporación del trabajo al capital en este sistema demanda que el obrero, ahora colectivo, sea dirigido en su quehacer, función que es enajenada de los operarios para recaer, en un primer momento, sobre la figura del capitalista.

Aglutinada ya la plantilla, se puede desplegar la división manufacturera del trabajo. Se fragmenta el proceso de trabajo y se reparte entre los diferentes obreros, cuya labor adquiere sentido únicamente al contemplarse como el desempeño de un órgano del obrero colectivo. Los trabajadores se enfrentan a una actividad segmentada sobre la que pueden verter toda su pericia manual. Ello combinado con la reducción de esfuerzos fútiles hace que la productividad del trabajo se dispare. La manufactura trastoca el "modo de trabajar de cada obrero, [...] lo revoluciona desde los cimientos hasta el remate y muerde la raíz de la fuerza de trabajo individual" (Marx, 1973a, p. 315); lo hace al precio de convertir al individuo en un mecanismo automático ya incapaz de reconocerse en el conjunto del proceso de trabajo. Esto repercute directamente en la estructura de la sociedad, que se acompasa a la del taller: la vitalicia atadura de los obreros a una actividad hace que se cristalice la jerarquía que surge del carácter especializado de la tarea y su retribución.

Pero, por sus propias limitaciones, la manufactura no puede "abarcar la producción social en toda su extensión, ni revolucionarla en su entraña” (Marx, 1973a, p. 322). Para eso se requiere de la implantación de la maquinaria. El eje de la revolución se desplaza de la fuerza de trabajo al medio de trabajo, convertido en máquina al eman- 
ciparse de la mano del operario. Se "sustituye al obrero que maneja una sola herramienta por un mecanismo que opera con una masa de herramientas" (Marx, 1973a, p. 328). Para operar sobre la máquina ya no se requiere fuerza muscular, lo que permite la entrada de mujeres y niños en la fábrica; además, se restringe la importancia de la destreza, lo que convierte a los empleados en engranajes reemplazables. Este movimiento, a la vez que degrada las condiciones laborales (debido a su pérdida de capacidad negociadora unida al surgimiento de una nutrida hueste de población obrera sobrante), dinamita las bases de la división del trabajo y sus jerarquías. Para llevarlo a cabo, el capital requiere usar la ciencia como una de sus potencias. Surge una forma de conciencia que, identificando las dinámicas que atañen a la producción social, "revoluciona constantemente la base técnica de la producción, y con ella las funciones de los obreros y las combinaciones sociales del proceso de trabajo" (Marx, 1973a, p. 437). El obrero parcial, para seguir este ritmo, debe ceder paso a un tipo de individuo capaz de insertarse en cualquiera de los puestos en que el capital le ubique. Un conocimiento científico que se extienda a lo largo del proceso de trabajo debe ser inoculado en la conciencia del conjunto de operarios, generalizando las capacidades como exige la permanente subversión de las condiciones productivas; exigencia que se realiza mediada por la presión también ejercida por la clase obrera mediante su lucha por reducir, distribuyendo, la jornada laboral.

No obstante, este avance encuentra un límite en la figura del capitalista. Esta clase, hasta donde hemos visto, combina en su ser la responsabilidad de coordinar a los obreros, por tanto, acapara una parte de la conciencia técnica, y la segmentación del capital global, a través de la propiedad de los medios de producción. La primera traba es paulatinamente descartada por el desarrollo de la acumulación, que introduce en órganos especializados del obrero colectivo todas las funciones de vigilancia y gestión inicialmente asociadas al propietario, que queda como una figura por completo 'superflua' (Marx, 1973b, p. 407). Pero para dejar atrás completamente este límite es preciso que el conjunto del capital se encuentre absolutamente centralizado, acabando con su forma fragmentaria. Esto solo puede alcanzarse a través de la "expropiación de los propietarios privados", lo que requiere de la acción revolucionaria de la clase obrera (Marx, 1973a, p. 699).

Sobre la base de la centralización completa del capital social global, se hace posible la superación del modo de producción capitalista gracias a la aparición y universalización de un tipo particular de actividad. El "trabajo científico general”, como lo llamó Marx (1972, p. 222) en sus borradores. Este trabajo nace y se expande gracias a la propia acción de los y las trabajadoras sobre sus propios atributos productivos: con "la conquista inevitable del poder político por la clase obrera conquistará también para la enseñanza tecnológica el puesto teórico y práctico que le corresponde en las escuelas del trabajo" (Marx, 1973a, p. 438). Tal es la más acabada forma de la producción de plusvalía relativa: la fusión de los conocimientos técnicos y científicos en el conjunto de la clase obrera por sus propios medios. Con ello el capital avanza hacia su "verdadero límite": su "conservación y valorización" colisiona con los "métodos de producción que [...] se ve obligado a emplear para conseguir sus fines y que tienden al [...] desarrollo incondicional de las fuerzas sociales productivas del trabajo" (Marx, 1973b, p. 272). La valorización del capital demanda la formación de personas que progresivamente puedan realizar el conjunto de labores reconociéndose en un proceso unitario de trabajo social y que, por ende, no necesiten enajenar el producto de su trabajo para reproducirse. El capital avanza hacia su extinción.

\section{La propuesta ciber-comunista}

El ciber-comunismo entiende que la "contradicción esencial" del modo de producción capitalista se haya condensada en el hecho de que la introducción del "principio de racionalidad objetiva [...] que posibilita el desarrollo de las fuerzas productivas" tenga lugar a partir de un "mecanismo ciego, como es el mercado" (Nieto, 2017b, p. 45). La propiedad privada haría que la humanidad no pudiera organizar de forma racional y democrática la evolución de sus propias fuerzas, ya que ésta operaría en un medio formado por incontables decisiones individuales orientadas hacia la obtención de beneficio. Esto se reflejaría por dos vías: una económica, que concierne al cómo la "anarquía" de la producción mercantil estrangularía el desarrollo productivo; $y$, con ella, otra política, dado que en una sociedad de clases los derechos y libertades no pueden ejercerse por completo, la democracia se vuelve un fraude (Nieto, 2017b, pp. 4647). La ruptura de estas ataduras tendría lugar a partir de la socialización de los medios de producción:

La diferencia esencial entre capitalismo y socialismo reside en la forma de regulación del proceso de reproducción económica: si es espontánea, por basarse en decisiones privadas autónomas [...] que se condicionan recíprocamente a posteriori, con la venta de los productos en el mercado, o si es un proceso conscientemente regulado por el conjunto de la sociedad de acuerdo con objetivos de desarrollo económico y social democráticamente elegidos (Nieto, 2017b, p. 61).

Planificando de forma racional a la vez que participativa - cosa que habilitarían las nuevas tecnologías- las actividades productivas se podría instalar una verdadera república democrática en la que se pudieran realizar las promesas de igualdad y fraternidad que el régimen capitalista no puede cumplir. Esa sería la forma en que la humanidad entraría en la "primera fase de la sociedad comunista", la "etapa socialista", que se regirá sobre la máxima "de cada cual según su capacidad a cada cual según su trabajo” (Nieto, 2017b, pp. 50-51).

Este socialismo se insertaría en una serie de etapas que cubrirían la evolución desde una economía competitiva de mercado a una completamente planificada, sin mercancías o dinero (Cockshott y Cottrell, 2006, 2017). El grueso de la propuesta ciber-comunista está centrada 
en demostrar la viabilidad, además de la idoneidad, de una planificación económica basada en tiempos de trabajo frente al mercado; idea que, junto a otras, toman de la Crítica del Programa de Gotha (así lo dicen, por ejemplo, en Cockshott y Cottrell, 2017, 2018; Nieto, 2017a). En este punto la propuesta encuentra sus dos bestias negras, que la acompañarán allá donde vaya: la teoría económica austríaca, en particular su teorema de la imposibilidad del cálculo económico, y la experiencia soviética, como intento preliminar y fallido de implantación del socialismo.

Los más grandes próceres de la escuela austríaca, desde Mises (1968) hasta Rothbard (1998), pasando por Hayek (1997), han hecho un importante esfuerzo por demostrar que el socialismo es ineficiente -cuando no imposible- debido a la cantidad de información que tendría que procesar un hipotético planificador para aproximarse siquiera a la eficiencia del mercando de concurrencia. La crítica que desde el ciber-comunismo se realiza a estos autores es ciertamente minuciosa; por lo que aquí nos interesa, bastará con mostrar algunas objeciones basadas en adelantos técnicos: Internet hace posible la recolección a tiempo real de información inicialmente dispersa; el Big-Data, por su parte, posibilita la concentración de tales datos; además, hoy existen superordenadores capaces de procesarlos rápidamente; $\mathrm{y}$, por último, con el empleo del pago electrónico mediante tarjetas se hace factible sustituir el dinero por "créditos laborales" (Cockshott y Cottrell, 2018, pp. 287-88). Gracias a estos avances, en la actualidad sería posible, nos dicen, dar el paso a una economía más eficiente y justa que la capitalista. Este tipo de argumentos de factibilidad dan una idea de por qué no pudo triunfar la experiencia soviética, pero no son suficientes.

Es cierto que la URSS sufría un importante "atraso del sistema de comunicaciones" (Cockshott y Cottrell, 2017, p. 107); pero las fallas de la planificación soviética no se debían únicamente a cuestiones de tipo técnico. La burocracia que se había instalado en el poder planificó como pudo la economía sin contar con la participación masiva del pueblo que exigiría un sistema más democrático y eficiente. A las carencias por la ausencia de condiciones materiales se unían las de carácter político. Así puede entenderse que las tentativas de generar algo así como una planificación cibernética quedaran en nada (cuando no fueron torpedeadas por la élite del Estado, como en la Unión Soviética, lo fueron por turbulencias como la irrupción de un golpe de estado militar que abortó el programa Cibersyn en el Chile de Allende). Sea como fuere, lo cierto es que no se prestó una "atención particular a la tecnología de la información como tecnología que posibilitaba el comunismo" (Cockshott y Cottrell, 2018, p. 284); sin ella resultaba imposible la participación del conjunto de la ciudadanía en la toma de decisiones respecto a qué, cómo o cuánto producir.

Con las enseñanzas de los extintos 'países del este' presentes, los ciber-comunistas se aventuran a ofrecer una propuesta más o menos detallada de cómo podrían corregirse sus fallas. Tal proyecto, el que respecta a la forma concreta de la planificación económica en base al tiempo de trabajo, resulta complejo y se encuentra dis- perso entre un nutrido conjunto de textos en muchos de los cuales se enfoca el problema de forma parcial o de polémica (véanse, además de los ya citados: Cockshott y Cottrell, 1993, 1997, 2008; Cottrell y Cockshott, 1993). En estas condiciones resulta en extremo difícil abordar la propuesta en su riqueza. Sin embargo, muchos de sus principios generales se hayan sintetizados por Nieto $(2017 \mathrm{a}, 2018)$. Este autor, que tomaremos como referencia, muestra cómo el trabajo, medido a través del tiempo, debería convertirse en el 'recurso clave', a partir del cual calcular tanto los costes de producción como las retribuciones (Nieto, 2017a, p. 150). Lo primero resulta posible a partir de los medios que nos ofrece el álgebra matricial, creando tablas insumo-producto que expresen el coste como "coeficientes de trabajo verticalmente integrados" (Nieto, 2017a, p. 151). Lo segundo, el sistema de retribución se estructuraría a partir de 'bonos laborales' que esquivarían la naturaleza monetaria al no poder circular y al únicamente ser accesibles a través del propio trabajo (Nieto, 2017a, p. 153).

Esta propuesta no implicaría que desaparezca la "desigualdad en el ingreso": primero porque quien decida trabajar más o más intensamente obtendrá mayor cantidad de ellos, y segundo porque existirán recompensas que permitan incentivar la participación en actividades menos deseadas o que se consideren necesarias y que motiven a los y las trabajadoras para conseguir los objetivos establecidos (Nieto, 2017a, p. 154, 2018, p. 316). Por lo que concierne a la distribución de bienes de consumo, se equilibrarían los precios en el corto plazo "aumentando los de alta demanda y disminuyendo los de baja demanda", y en el medio plazo, "si las diferencias entre oferta y demanda persisten", modificando las cantidades producidas, "aumentando la producción de bienes cuya relación precio/coste sea superior a la promedio y disminuyéndola en caso contrario" (Nieto, 2017a, p. 162).

Desde estas premisas, la planificación tendría lugar a partir de un proyecto que involucrase activamente a la ciudadanía en su elaboración y ratificación, gracias a la aplicación de las tecnologías de la información. Con ellas se podría conciliar a diferentes escalas - de la "macro" a la más "detallada"- la producción y el consumo con gran acierto, así como corregir casi de inmediato los desajustes (Nieto, 2017a, pp. 155-61, 2018, pp. 313-15). Todo esto se desenvolvería en un ecosistema en el que la inmensa mayoría de las empresas serían de titularidad colectiva, quedando la producción privada restringida a ciertos ámbitos de difícil inclusión en el plan, productores de bienes que requieran gran personalización, o que ofrezcan la posibilidad de "innovación" (Nieto, 2017a, p. 163-5, 2018, p. 322). Con esto quedaría grosso modo perfilado un posible porvenir socialista.

\section{Ordenadores y transición al comunismo}

Es importante problematizar tanto el punto de partida del ciber-comunismo, la forma en que inserta su propuesta en la transición al comunismo, como el papel de su desarrollo concreto, la planificación económica 
computarizada. Para ello, trataremos de diseccionar, en dos apartados diferentes, los puntos más problemáticos, pero también los más interesantes, de su propuesta, empezando por aquello que entienden por "comunismo" y avanzando hasta situar las nuevas tecnologías en el lugar que podrían ocupar en su consecución.

\subsection{Acerca de la noción de comunismo}

Para discutir sobre una noción tan polémica, partiremos del esquema que nos brinda Barata-Moura (1997). El comunismo, nos dice, debe tomarse a partir de tres planos íntima e indisolublemente relacionados: ontológicamente como un movimiento real a conocer, políticamente como un programa para la transformación social, y en un nivel material concreto como un tipo de sociedad nueva a la que llegar. Más que para condensar o clasificar las citas que pueden hallarse en la obra marxiana, esta tríada debe servir para configurar un marco en el que comprender y transformar el modo de producción capitalista. Entendemos que el comunismo, o el socialismo -debemos hacer notar, preliminarmente, que nosotros usaremos ambas nociones, siguiendo al propio Marx, como "términos equivalentes y alternativos" (Chattopadhyay, 2015, p. 72)-, es un tipo de metabolismo social diferente y posterior al capitalista que, sin embargo, está inserto como potencia en su propio movimiento y que se halla portado en determinaciones específicamente políticas.

De entre los escasos fragmentos en que Marx alude a un metabolismo social post-capitalista, destacan aquellos que lo describen como "una asociación de hombres libres que trabajen con medios colectivos de producción y desplieguen sus numerosas fuerzas individuales de trabajo, con plena conciencia de lo que hacen, como una gran fuerza de trabajo social" (Marx, 1973a, p. 45); o como aquel tipo de organización en que los "productores asociados regulen racionalmente [...] su intercambio de materias con la naturaleza, lo pongan bajo su control común en vez de dejarse dominar por él como por un poder ciego", y con ello hagan que un verdadero "reino de la libertad" florezca sobre el "reino de la necesidad" (Marx, 1973b, p. 827). Ambas formulaciones responden a un tipo de sociedad que en su conjunto ha desarrollado una conciencia científico-técnica que abarca el conjunto del proceso productivo. Hablaríamos de una forma de regir las potencias humanas en la que los agentes conocen las necesidades que sobre ellos operan y que, por tanto, actúan prescindiendo de la enajenación, esto es, libremente (tal es la noción de libertad que ofrece Engels, 1975).

Diferente es la forma de entender el socialismo que emana de la lectura del texto de cabecera del ciber-comunismo, la Crítica del Programa de Gotha. En este opúsculo aparecen -y, hasta donde sabemos, solo en éluna serie de proposiciones que han generado gran cantidad de controversias. Según el texto, una vez que los "trabajos individuales no forman ya parte integrante del trabajo común mediante un rodeo, sino directamente", la sociedad entra en un periodo en que el productor obtiene de ella "exactamente lo mismo que ha dado" a través de un sistema que, curiosamente, rechazó en diversas ocasiones: bonos que consignen el trabajo invertido (Marx, 1971, p. 21). En este estadio, aunque ya nadie pueda vivir sin trabajar y no exista propiedad privada sobre los medios de producción, en lo referente a la distribución, "rige el mismo principio que en el intercambio de mercancías equivalentes" (Marx, 1971, p. 22). Tras esta etapa vendría la fase superior de la sociedad comunista: una sin división social del trabajo, ni oposición entre trabajo manual e intelectual, en la que el desarrollo de las fuerzas productivas dé lugar a una abundancia tal que permita a la sociedad "escribir en su bandera: ¡De cada cual, según sus capacidades; a cada cual, según sus necesidades!" (Marx, 1971, p. 24)

Además de estas dos fases menciona que entre la 'sociedad capitalista' y la 'comunista' media un "periodo político de transformación, cuyo Estado no puede ser otro que la dictadura revolucionaria del proletariado" (Marx, 1971, p. 38). La tradición leninista entendió que en este punto Marx hablaba de aquella primera fase del comunismo; sin embargo, al atender a la literalidad del texto, nos percatamos de que la secuencia planteada de manera más fiel sería: sociedad burguesa, dictadura del proletariado y comunismo, dentro del cual se incluirían las dos fases mentadas.

El grueso del problema, más que en el número de periodos doctrinalmente establecidos entre el modo de producción capitalista y el comunismo, reside en que en ningún momento se hace alusión a cómo se pasará de uno a otro periodo. No hay mediación que nos permita seguir el desarrollo concreto. Esta falencia es, consideramos, compartida por el leninismo y la propuesta ciber-comunista, llegando a ser el punto más débil de su argumentación. Ofreciendo una cantidad razonable de medidas transicionales hacia esa primera etapa del socialismo (resumidas en: Cockshott y Cottrell, 2018), e incluso aventurándose a describir con un cierto nivel de detalle cómo funcionaría la economía en este periodo (nuevamente: Nieto 2017a), poco nos dicen sobre cómo se transita de una etapa del comunismo a la siguiente.

Cuando Cockshott enfoca directamente la cuestión, lo hace usualmente a través de la confrontación con los leninistas, muy particularmente respecto a la forma en la que estos interpretan el eslogan: "de cada cual, según sus capacidades; a cada cual, según sus necesidades". Esta corriente habría entendido la distribución ilimitada de bienes en función de necesidades como la "provisión de bienes de consumo gratis o subsidiados" (Cockshott y Cottrell, 2006, p. 175, 2017, p. 112). Esta concepción errada, al combinarse con el pago monetario -no en bonos-, habría llevado a la URSS a un tipo de cálculo económico que frenaba la productividad del trabajo, con lo que se convertía el comunismo en una ilusión, pues la meta de la distribución gratuita se veía cada vez más inalcanzable. Frente a ello, se propone regresar a la literalidad de la consigna para diferenciar entre el reparto gratuito e ilimitado - que sería un absurdo-y la dispensación de bienes en función de las necesidades, lo que ya se prefigura en los Estados del bienestar, al ofrecer 
prestaciones a las personas que las requieren (Cockshott y Cottrell, 2006, 2017).

Los ciber-comunistas, so pretexto de convertir el comunismo en algo accesible, lo privan de sus determinaciones más elementales, quedando reducido casi a una cuestión de cálculo y distribución. Apenas queda rastro de aquella plena conciencia sobre la actividad; no digamos ya de la posibilidad de suprimir la división entre trabajo manual e intelectual que aparece en el texto al que con tanta recurrencia aluden. Una sociedad en la que se atienda a las personas que lo necesiten de acuerdo a lo que precisen les resulta, sin duda, más sencillamente imaginable que una sin Estado ni clases, algo que relegan a una quimera, justificada si acaso como una suerte de guía moral, de horizonte inalcanzable. El comunismo deja de poder reconocerse en el movimiento 'positivo' del modo de producción capitalista y se transforma en lo que Martínez Marzoa (2018) llama un 'conceptolímite'. Formular esta legítima apuesta, definir el comunismo como - lo que consideran- es su primera fase, negando la factibilidad de la segunda, debería transitar por aceptar que, al menos en ese punto, se distancian significativamente de la crítica de la economía política. No hacerlo o, más aún, hacer pasar la planificación de la economía mediada por mecanismos democráticos por la regulación libre y consciente del metabolismo social, resulta al menos poco honesto.

\subsection{La centralización política del capital y el-posible- papel de la computación en la extinción del modo de producción capitalista}

Ya dijimos que la evolución del modo de producción capitalista al comunismo implicaba la unificación del conjunto del trabajo social en un solo órgano, algo que realizaría la posibilidad de que "todo el capital social existente se reuniese en una sola mano" (Marx, 1973a, p. 572). Según lo concebimos, este extremo únicamente puede alcanzarse a través de la centralización del capital social en su forma política: el Estado moderno ${ }^{2}$. Esta institución convierte en genuinamente política, entre otras, la lucha de la clase obrera por tomar las riendas de la gestión del capital. Gracias a la expansión del ámbito de acción del Estado puede consumarse por completo el proceso -que encontró un hito fundamental en la formación de las sociedades anónimas- de degradación de la propiedad privada personal que porta el modo de producción capitalista. Adjudicándose la propiedad sobre los medios de producción, haría que el conjunto de la clase obrera participe de ella mediante la condición de ciudadanía. Se trataría de la "supresión del régimen de producción capitalista dentro del propio régimen de producción capitalista" que "aparece prima facie como sim-

\footnotetext{
Esta visión del Estado, aunque tiene su origen en citas de Marx (1973b, p. 799), de quien se toma la expresión de 'forma política', y de Engels (1975, p. 339), quien propuso la fórmula del 'capitalista colectivo ideal', no fue desarrollada hasta muchos años después, con la llamada 'escuela alemana de la derivación' (Holloway y Picciotto, 1978). Sin embargo, nuestra perspectiva se aproxima más a la elaborada por Íñigo Carrera (2013), y más aún a la expuesta en Rodríguez Rojo (2019). Así, consideramos al Estado, no como un ente externo a la economía o al capital, sino como una forma de expresión de la unidad del capital social, inicialmente nacional y, finalmente, mundial.
}

ple fase de transición hacia una nueva forma de producción", una "especie de producción privada, pero sin el control de la propiedad privada" (Marx, 1973b, p. 458).

La organización de toda la producción por el Estado -una dictadura del proletariado, esto es, una república democrática desarrollada-, que compraría el conjunto de la fuerza de trabajo, a la que proveería de las mercancías que requiere su reproducción, no es, más que en su apariencia inmediata, ningún tipo de superación del modo de producción capitalista. Al contrario, es su manifestación más eficaz, el sumun de la extracción sistemática de plusvalor. De hecho, es la única expresión del capital capaz de desplegar sus potencias hasta el punto de hacerse incompatible consigo mismo.

Esta concepción choca con la de los autores del cibercomunismo. Según su perspectiva, "la cuestión crucial es [...] si las unidades de la producción se reproducen a través de relaciones mercantiles, y para que esto sea así -es decir, para que la ley del valor lo regule-debe existir la posibilidad de quiebra" (Cockshott y Cottrell, 2017, p. 86). Se identifica modo de producción capitalista con imperio del mercado en un relato que bebe del mismo manantial que quienes entienden como "menos capitalista" el hecho de que, por ejemplo, el Estado impida la bancarrota de los grandes bancos; un destello de su propuesta que comparten, sorprendentemente, con los mismos economistas liberales que con tanto ahínco rebaten.

Para que existan mercancías o dinero, o para que opere la ley del valor, no es necesario que el fracaso de las unidades productivas se exprese inmediatamente en su desaparición. Además, esa afirmación resulta contradictoria con otras formuladas, por ejemplo, al reconocer como monetaria (y, por tanto, mercantil) la forma de pago que predominaba en la URSS. El valor puede realizarse, y el dinero conservar sus más esenciales funciones, sin necesidad de concurrencia competitiva; y eso no dejará de ocurrir mientras la producción no se rija conscientemente (algo que efectivamente podría tener lugar en el socialismo, pero en ningún caso en un futuro próximo). Hasta entonces no queda otra opción que la de enajenar en el capital la dirección de la producción social, dejando como mediata, y por ende imperfecta, la unión entre producción y consumo sociales. El dinero, por su parte, continuará engrasando el metabolismo social, aunque se lo presente como bono laboral, por ejemplo, para recalcar la inexistencia de clases parasitarias que se nutran del producto del trabajo social sin aportar a él. La pretensión de instaurar un sistema de vales horarios se sustenta en la ilusión, compartida por Cockshott y la economía política, de que el valor puede expresarse directamente como cantidades de trabajo (véase Íñigo Carrera, 2007).

A lo que sí se podría aspirares a establecer mecanismos de corrección y reajuste de cantidades y precios más eficientes y menos caóticos, lo que, creemos, sería factible aplicando los medios que nos brindan las nuevas tecnologías. En este punto la aportación del ciber-comunismo sí resulta de sumo interés.

El capital social centralizado requiere (como requirieron los Estados de tipo soviético) de técnicas de organización más o menos eficientes de la producción. 
Disponer y hacer uso de los modernos medios de cálculo y administración de información tal y como describen los ciber-comunistas puede resultar crucial en ese propósito. Tanto es así que en la actualidad sería impensable la no aplicación de algún tipo de dispositivo digital a cualquier proyecto de tamaña escala. No es casualidad que ellos mismos encuentren el germen de lo que llaman socialismo en las formas más potentes y avanzadas del capital: la "gestión informatizada de insumos y productos en una economía socialista funcionaría de forma similar a como gestionan hoy la cadena de suministros empresas como Amazon o Wal-Mart" (Nieto, 2018, p. 314). Estas empresas ya gestionan volúmenes de productos superiores a los de muchos Estados, y lo hacen de manera en extremo coordinada gracias, justamente, a procedimientos que, movidos por algoritmos, diseñan las formas óptimas de llevar a cabo las operaciones. En este punto aparece la potencialidad revolucionaria que llevan consigo las tecnologías de la información: ofrecen al capital -especialmente al capital totalmente centralizado- una forma de poner en marcha la producción mucho más eficiente que otras anteriores.

Hoy podemos ver cómo la inserción de estos artilugios está revolucionando la producción y, con ella, nuestras vidas. Las TICs, como, por ahora, última etapa del desarrollo de la maquinaria, llevan esa revolución más allá de las fábricas. Para abastecerse de fuerza de trabajo útil el capital extiende la formación a inmensos contingentes de obreros, cuyos niveles educativos se han incrementado gracias a la implantación de sistemas de enseñanza masivos. Con este despliegue nos situamos, creemos, notablemente más cerca de una "educación del porvenir" que forje a los "hombres plenamente desarrollados" que en los tiempos en que Marx (1973a, p. 434) escribía. A la implantación de una economía automatizada la acompaña un ensanchamiento gradual de una conciencia técnica que no puede expresarse, como tantas otras tendencias históricas de la acumulación del capital, más que contradictoriamente. Ciertos órganos del obrero colectivo son dotados de un espectacular refinamiento en sus aptitudes productivas a expensas de que otros sean reducidos a apéndices de la máquina (tal vez ya no introduciendo objetos en un aparato mecánico, sino atendiendo llamadas frente a un ordenador) o directamente repudiados por el capital y lanzados como despojos a la marginación (ahora agravada en su nuevo aspecto digital). Esta fragmentación, como ya apuntamos, pensamos que podría llegar a ser trascendida -junto con el modo de producción que la genera- a través de una lucha de clases que, reclamando la reducción de las jornadas laborales en defensa del valor de la fuerza de trabajo, fuerce al capital a desarrollar aún más las fuerzas productivas y universalizar las cualidades técnicocientíficas.

\section{Conclusiones}

En el artículo hemos tratado de exponer qué herramientas nos ofrece la crítica marxiana de la economía política para entender la superación del modo de producción capitalista. El momento clave en este proceso, hemos concluido, se encuentra en la forma en que la clase obrera se adapta al sistema de maquinaria, al que esta misma obliga al capital a recurrir para aumentar la tasa de plusvalía sobre la base de su absoluta centralización. Una vez elaborado este punto, tratamos de sintetizar la propuesta ciber-comunista, consistente, a grandes rasgos, en demostrar cómo la aplicación de medios computacionales a la planificación económica puede generar un entorno eficiente sobre el que se yerga una verdadera república que ponga rumbo al comunismo. Por último, hemos discutido esta valiosa contribución en dos tiempos: primero, polemizando con la propia noción de comunismo como algo cualitativamente distinto a un metabolismo social planificado de forma democrática; y segundo, estableciendo de forma escueta la importancia del papel tanto del Estado como de la informática en la transición al socialismo.

No podemos aún saber si estamos presenciando ya avances que acercarían a la humanidad a la liberación del yugo del capital. De hecho, tampoco podemos más que imaginar, con mucho esfuerzo, cómo viviremos como 'productores asociados'. Pero no era ese el propósito de este trabajo. Lo que con este recorrido podemos afirmar es que la propuesta del ciber-comunismo tiene una inequívoca fortaleza política, aunque, sin embargo, yerre a la hora de ubicar la situación que con tanto detalle describe como parte de un metabolismo social de tipo socialista.

Una sociedad en que la economía se encuentre planificada a partir de un organismo político de corte democrático no constituiría, consideramos, la superación del modo de producción capitalista. No obstante, y tal vez sea este el punto central, creemos poder afirmar que constituye la manifestación más potente y progresista del capital. En este sentido, la praxis política de la clase obrera orientada a su consecución sería - conscientemente o no- parte integrante de la lucha por la realización del socialismo. Se trata de un movimiento que porta, entonces, los aspectos del capital que lo llevan hacia su propia desaparición. En ese proceso, las nuevas tecnologías podrían jugar un papel importante como la dilatación de la conciencia científica de la clase obrera gracias a la optimización de la planificación económica que estas tecnologías permiten. Sin embargo, para llegar al punto en que el ser humano haya dejado atrás la enajenación capitalista, por desgracia, seguramente aún quede por sufrir buena parte de aquel "largo y doloroso alumbramiento" que, según Marx (1971, p. 23), traería al mundo una sociedad realmente libre.

\section{Agradecimientos}

Agradecemos encarecidamente a los compañeros del grupo CibCom, especialmente a Maxi Nieto, su apertura a la discusión de estos y tantos otros temas. También agradecer a los miembros del CICP y muy singularmente a Gastón Caligaris el material e ideas que han brindado. 


\section{Referencias}

Barata-Moura, J. (1997). Materialismo e subjectividade. Lisboa: Avante!

Chattopadhyay, P. (2015). El mito del socialismo del siglo XXI y la permanente relevancia de Karl Marx. En De regreso a Marx. (M. Musto, pp. 69-104). Buenos Aires: Octubre.

Cockshott, Paul, y Cottrell, A. (1993). Toward a New Socialism. Nottingham: Bertrand Russell Press.

Cockshott, P. y Cottrell, A. (1997). Labor-time versus alternative value bases: a research note. Cambridge Journal of Economics, $27,545-49$.

Cockshott, P. y Cottrell, A. (2006). El valor y los modelos económicos socialistas. En Derecho a decidir. (J. Arriola, pp. 143-88). Barcelona: El viejo topo.

Cockshott, P. y Cottrell, A. (2008). Computadores y democracia económica. Revista de economía institucional 10(29), 161-205.

Cockshott, P. y Cottrell, A. (2017). Argumentos para un nuevo socialismo. En Ciber-comunismo (P. Cockshott y M. Nieto, pp. 78-133). Madrid: Trotta.

Cockshott, P. y Cottrell, A. (2018). Planificación económica, ordenadores y valores-trabajo. En Qué enseña la economía marxista. (D. Guerrero y M. Nieto, pp. 265-94). Madrid: El viejo topo.

Cottrell, A. y Cockshott, P. (1993). Socialist planning after the collapse of the Soviet Union. Revue Européenne des Sciences Sociales, 96(31), 167-85.

Engels, F. (1975). Anti-Düring. La Habana: Instituto Cubano del Libro.

Hayek, F. (1997). La fatal arrogancia. Madrid: Unión.

Holloway, J. y Picciotto S. (Eds.) (1978). State and capital. London: Edward Arnold.

Ínigo Carrera, J. (2007). Conocer el capital hoy. Usar críticamente El capital.1. Buenos Aires: Imago Mundi.

Íñigo Carrera, J. (2013). El capital: razón histórica, sujeto revolucionario y conciencia. Buenos Aires: Imago Mundi.

Martínez Marzoa, F. (2018). La filosofia de El capital. Madrid: Abada.

Marx, K. (1971). Crítica del Programa de Gotha. Madrid: Ricardo Aguilera.

Marx, K. (1972). Elementos fundamentales para la crítica de la economía política.2. Madrid: Siglo XXI.

Marx, K. (1973a). El capital. I. La Habana: Editorial de Ciencias Sociales.

Marx, K. (1973b). El capital. III. La Habana: Editorial de Ciencias Sociales.

Mises, L. (1968). El socialismo. Buenos Aires: Western Books Foundation.

Nieto, M. (2017a). El mecanismo de funcionamiento de una economía socialista democráticamente planificada. En Cibercomunismo (P. Cockshott y M. Nieto, pp. 142-68). Madrid: Trotta.

Nieto, M. (2017b). El proyecto comunista: significado histórico y rasgos básicos. En Ciber-comunismo (P. Cockshott y M. Nieto, Pp. 45-77). Madrid: Trotta.

Nieto, M. (2018). La eficiencia dinámica de la economía planificada. En Qué enseña la economía marxista. (D. Guerrero y M. Nieto, pp. 295-330). Madrid: El viejo topo.

Rodríguez Rojo, J. (2019). La revolución en El capital. Madrid: Garaje.

Rothbard, M. (1998). Man, Economy, and State. Auburn: Ludwig von Mises Institute.

Starosta, G. (2015). Marx's Capital. Method and Revolutionary Subjectivity. Chicago: Haymarket.

Starosta, G, y Caligaris, G. (2017). Trabajo, valor y capital. Bernal: Universidad de Quilmes. 